\title{
Effect of environmental and socioeconomic factors on the use of dental floss among children: a hierarchical approach
}

\section{Renita Baldo MORAES(a) \\ Beatriz Baldo MARQUES(a) \\ Diana Maria Pigatto COCCO(a) (iD \\ Jessica Klöckner KNORST(b) \\ Fernanda TOMAZONI(b) ID \\ Thiago Machado ARDENGHI(b) (iD}

(a) Universidade de Santa Cruz do Sul UNISC, Department of Nursing and Dentistry, University of Santa Cruz do Sul, Santa Cruz do Sul, RS, Brazil.

(b) Universidade Federal de Santa Maria UFSM, School of Dentistry, Department of Stomatology, Santa Maria, RS, Brazil.

Declaration of Interests: The authors certify that they have no commercial or associative interest that represents a conflict of interest in connection with the manuscript.

Corresponding Author:

Thiago Machado Ardenghi

E-mail: thiardenghi@hotmail.com

Submitted: May 13, 2019

Accepted for publication: September 1, 2019

Last revision: September 24, 2019
Abstract: The aim of this study was to evaluate the association of environmental and socioeconomic characteristics with the use of dental floss in preschool children. This cross-sectional study was conducted with a sample of 402 preschool children aged 1-5 years, from Santa Cruz do Sul, a Southern city in Brazil. Mothers answered questions about environmental, demographic, and socioeconomic characteristics. Behavior variables as use of dental floss (study outcome) and dental attendance were also evaluated. Poisson regression analysis with robust variance through a hierarchical approach was used to investigate the association of explanatory variables for use of dental floss. Prevalence ratio (PR) and 95\% confidence intervals $(95 \% \mathrm{CI})$ were estimated. The mean sample age was 3.32 years (standard deviation [SD] 1.10). Of the included children, 291 (73.12\%) did not use dental floss. The environmental model indicated that children who attended daycare (PR 2.53; 95\%CI 1.39-4.60) and those whose parents were members of volunteer networks (RP 1.58; 95\%CI 1.02-2.46) were more likely to use dental floss. Children from families with higher income (PR 1.55; 95\%CI 1.07-2.24) and maternal schooling (PR 2.21; 95\%CI 1.31-3.74) presented a higher prevalence of dental floss use. Older children and those who attended dental services were also related to higher dental floss use. Our findings suggest that children who live in a supporting environment and those with a higher socioeconomic status are more likely to use dental floss.

Keywords: Child; Dental Devices, Home Care; Oral Hygiene; Social Environment; Socioeconomic Factors.

\section{Introduction}

Oral health is fundamental for the well-being of individuals. It has been considered an integral part of general health and important for establishing a good quality of life. ${ }^{1,2}$ In this context, alterations in oral health can influence well-being, social relations, and daily functions, with consequences for individuals and their families. ${ }^{3,4,5}$ Thus, oral health promotion has a paramount importance, especially among preschool children, in enabling children to enjoy a healthy future. ${ }^{6}$ 
The process of habits acquisition starts in the individuals' first years of life. ${ }^{7}$ This period has a fundamental importance in people's lives and may have long term repercussions. ${ }^{7}$ Oral hygiene is an example of these habits. It has been recommended that children's oral hygiene be performed by an adult since the eruption of the first tooth. ${ }^{8}$ Stimulating the development of appropriate hygiene habits such as dental floss use in this age group may be important in the prevention of future oral diseases. . $, 6,7^{2,7}$

Parents are primarily responsible for the healthcare of preschool children. Therefore, several factors may be related to the promotion and maintenance of oral health in this population. Lower socioeconomic status has been related to poorer oral healthcare and worse outcomes in children. ${ }^{9,10}$ Equally important, environmental factors may link the several distal determinants with the more proximal influences of health outcomes. ${ }^{11,12}$ Literature has demonstrated that aspects related to the environment may also influence people's behaviors and health. ${ }^{13,14}$ Thus, it is important to consider the source of environment variability of different hierarchical levels. ${ }^{15}$

In this context, the influence of environmental and socioeconomic characteristics on oral health habits should be considered. However, evidence about factors related to the use of dental floss by preschool children is scarce. Systematic reviews have been performed to investigate the association between dental floss and interproximal dental caries among childern ${ }^{7,16}$ with only one study showing evidence of the relationship in primary dentition. However, the use of dental floss should never be discouraged. Healthy habits acquired in childhood may persist throughout adult life, with numerous oral and general health benefits. ${ }^{7,17}$ Thus, the aim of this study was to evaluate the association of environmental and socioeconomic characteristics with the use of dental floss in preschool children. We hypothesized that children with better environmental and socioeconomic conditions were more likely to use dental floss.

\section{Methodology}

This study is reported according to STROBE (Strengthening the Reporting of Observational Studies in Epidemiology) guidelines.

\section{Study design and sample}

This cross-sectional study included 402 preschool children from Santa Cruz do Sul, a southern city in Brazil. In 2010, the city had an estimated population of 118,374 individuals, which included 5,890 children under 6 years of age. ${ }^{18}$ A sample of children from 1 to 5 years old who attended health centers in the municipality on the National Children's Vaccination Day was selected. Eleven health centers were selected from different regions of the city. Health Units (BHU), Family Health Strategies (FHS) units, and the Maternal and Child Center (MCC) were included.

The sample size was estimated considering a standard error of 5\%, a 95\% confidence level, and an odds ratio of 2.65 in the exposed group (high socioeconomic level). ${ }^{19}$ The ratio of unexposed to exposed was $1: 2$ and the statistical power $80 \%$. Twenty percent was added to compensate for losses and a final sample of 352 children was thus calculated. The inclusion criteria were children aged 1 to 5 years who attended health centers in the municipality on the National Children's Vaccination Day. The exclusion criteria comprised children with any degree of mental or physical disability.

\section{Data collection}

Data collection was conducted on the " $\mathrm{D}$ " day of the National Multivacination Campaign in 2016. It included clinical examination of the children and structured interviews with the mothers. A team with an examiner, a scorer, and an interviewer performed data collection at each health center. Interviews were conducted using questionnaires to obtain data on demographic, socioeconomic, behaviors, and environmental characteristics. The interviewers underwent a training and calibration process with theoretical discussions and practice, following the method described in the manual for epidemiological surveys by the World Health Organization. ${ }^{20} \mathrm{~A}$ pilot study of 10 child and mother pairs (who were not part of the sample) was carried out to test the methodology and the applicability of the questionnaires.

The outcome of this study was the use of dental floss, which was assessed with the question: "Does 
your child use dental floss?" and the possible responses were $0=$ no and $1=$ yes. This question has been used in previous studies. ${ }^{19,21}$ Environmental variables were assessed using two questions: "Do you attend a volunteering group?", and "Does your son or daughter attend daycare?", with $0=$ no and $1=$ yes responses. Children were also classified according to their use of dental services (behavior variable) as: $0=$ yes and $1=$ no.

Children's socioeconomic and demographic characteristics were also collected. Information about sex (female or male), age ( $<4$ years $\geq 4$ years), race, maternal educational level, and household income were obtained. Race was recorded according to the criteria of the Brazilian Institute of Geography and Statistics (White, Brown, Black, Yellow, Indigenous) and then dichotomized as "white" or "non-white". 18 Maternal education was collected in years of study and categorized as $<8$ years (incomplete primary education) or $\geq 8$ years. Household income was collected in Brazilian reals (exchange rate was 3.75 reals to 1 US dollar, approximately) as the sum of all incomes in a month and was categorized in tertiles: T1 (lowest); T2 (medium), and T3 (highest).

\section{Statistical analysis}

Data were analyzed using Stata 14 program (StataCorp LP, College Station, TX, USA). Descriptive statistics were used to describe the environmental, socioeconomic, demographic, and behavioral characteristics of the sample. Multivariate Poisson regression analysis with robust variance was performed to assess the associations between independent variables and the use of dental floss.

A hierarchical analysis was used to identify changes in the associations as different groups of variables were included. We used a previous contextual framework to build the multiple models (Figure), adapted from the World Health Organization..$^{22}$ We first constructed a model with environmental variables (block 1 ), then a model with demographic variables (block 2), another with socioeconomic variables (block 3 ), and a full model by adding the behavior variable (block 4 ). The plausibility and adjustment of the models were considered during model building. Variables with
Environmental variables

Block 1

Attend school;

- Member of volunteer networks;

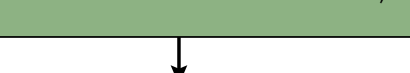

Demographic variables

Block 2

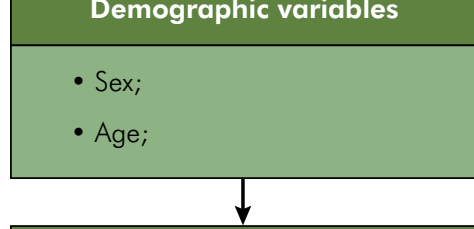

Socioeconomic variables

Block 3



Behavior variable

Block 4

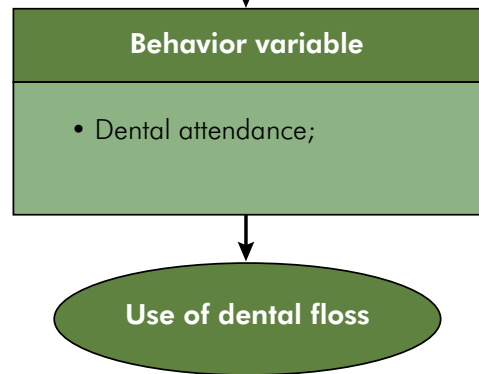

Figure. Theoretical framework for the multiple hierarchical model. ${ }^{22}$

p-value $<0.10$ in the univariate Poisson regression analysis were incorporated into the hierarchical model. Prevalence ratios (PR) and respective 95\% confidence intervals (CI) of each exposure variable in relation to the outcomes were estimated.

\section{Ethical issues}

This study was approved by the Committee for Ethics in Research of the University of Santa Cruz do Sul (protocol number 1.625.441) and the participants' parents signed a consent form.

\section{Results}

A total of 402 preschool children participated in this study (85.5\% response rate). The reason for losses was refusal to take part in the study $(n=68)$. The mean age was 3.32 years (standard deviation 
[SD] 1.10). Regarding the outcome, 291 (73.1\%) of the children did not use dental floss.

Table 1 summarizes the characteristics of the sample according to the independent variables and the use of dental floss. Most children were girls (53.0\%) and from the lower income categories. Most children (78.0\%) attended daycare and 9.5\% had parents who were members of volunteer networks. The majority of children who did not use dental floss were male, non-white, and from low socioeconomic status.

The unadjusted association of the variables with use of dental floss are presented in Table 2 . There were statistically significant differences for environmental variables (attending daycare and member of volunteer network) and use of dental floss ( $p<0.05)$. Furthermore, the use of dental floss was significantly different among income tertiles,

Table 1. Characteristics of the sample according to independent variables and use of dental floss $(n=402)$.

\begin{tabular}{|c|c|c|c|}
\hline \multirow{2}{*}{ Variables } & \multirow{2}{*}{$n(\%)$} & \multicolumn{2}{|c|}{ Use of dental floss [n (\%)] } \\
\hline & & No & Yes \\
\hline \multicolumn{4}{|l|}{ Environmental variables } \\
\hline \multicolumn{4}{|l|}{ Attend school } \\
\hline No & $85(21.1)$ & $74(88.1)$ & 10 (1 1.9) \\
\hline Yes & $317(78.9)$ & $217(69.1)$ & $97(30.9)$ \\
\hline \multicolumn{4}{|l|}{ Member of volunteer networks } \\
\hline No & $361(90.5)$ & $266(74.5)$ & $91(25.5)$ \\
\hline Yes & $38(9.5)$ & $22(57.9)$ & $16(42.1)$ \\
\hline \multicolumn{4}{|l|}{ Demographic variables } \\
\hline \multicolumn{4}{|l|}{ Sex } \\
\hline Female & $213(53.0)$ & $145(69.0)$ & $65(31.0)$ \\
\hline Male & $189(47.0)$ & $146(77.7)$ & $42(22.3)$ \\
\hline \multicolumn{4}{|l|}{ Age } \\
\hline$<4$ years & $198(49.3)$ & $161(82.6)$ & $34(17.4)$ \\
\hline$\geq 4$ years & $204(50.7)$ & $130(64.0)$ & $73(36.0)$ \\
\hline \multicolumn{4}{|l|}{ Race } \\
\hline White & $315(78.4)$ & $222(71.4)$ & $89(28.6)$ \\
\hline Non-white & $87(21.6)$ & $69(79.3)$ & $18(20.7)$ \\
\hline \multicolumn{4}{|l|}{ Socioeconomic variables } \\
\hline \multicolumn{4}{|l|}{ Maternal education } \\
\hline$<8$ years of formal education & $121(30.4)$ & $104(87.4)$ & $15(12.6)$ \\
\hline$\geq 8$ years of formal education & $277(69.6)$ & $183(66.5)$ & $92(33.5)$ \\
\hline \multicolumn{4}{|l|}{ Household income in $R \$^{a}$} \\
\hline Lowest ( $1^{\text {st }}$ tertile) & $160(41.0)$ & $123(77.8)$ & $35(22.1)$ \\
\hline Medium ( $2^{\text {nd }}$ tertile) & $133(34.1)$ & $104(78.2)$ & $29(21.8)$ \\
\hline Highest ( $3^{\text {th }}$ tertile) & $97(24.9)$ & $55(57.9)$ & $40(42.1)$ \\
\hline \multicolumn{4}{|l|}{ Behavior variable } \\
\hline \multicolumn{4}{|l|}{ Dental attendance } \\
\hline No & $163(40.8)$ & $144(89.4)$ & $17(10.6)$ \\
\hline Yes & $237(59.3)$ & $145(61.7)$ & $90(38.3)$ \\
\hline
\end{tabular}

Values lower than 402 due to missing data; ${ }^{\circ}$ Brazilian real exchange rate was $\mathrm{R} \$ 3.75$ to US $\$ 1.00$ approximately). 
maternal education, and dental attendance categories $(\mathrm{p}<0.05)$. Regarding to demographic characteristics, there were statistically significant differences for age and sex $(\mathrm{p}<0.05)$.

Table 3 shows the adjusted association of variables with use of dental floss, determined through the hierarchical approach. In the environmental

Table 2. Unadjusted association of variables with use of dental floss, determined using Poisson regression with robust variance.

\begin{tabular}{|c|c|c|}
\hline Variables & $\mathrm{PR}^{\mathrm{a}}(95 \% \mathrm{Cl})^{\mathrm{b}}$ & $p$-value \\
\hline \multicolumn{3}{|l|}{ Environmental variables } \\
\hline \multicolumn{3}{|l|}{ Attend school } \\
\hline No & 1.00 & \multirow[t]{2}{*}{0.002} \\
\hline Yes & $2.59(1.41-4.45)$ & \\
\hline \multicolumn{3}{|l|}{ Member of volunteer networks } \\
\hline No & 1.00 & \multirow[t]{2}{*}{0.017} \\
\hline Yes & $1.65(1.09-2.49)$ & \\
\hline \multicolumn{3}{|l|}{ Demographic variables } \\
\hline \multicolumn{3}{|l|}{ Sex } \\
\hline Female & 1.00 & \multirow[t]{2}{*}{0.056} \\
\hline Male & $0.72(0.51-1.00)$ & \\
\hline \multicolumn{3}{|l|}{ Age } \\
\hline$<4$ years & 1.00 & \multirow[t]{2}{*}{0.000} \\
\hline$\geq 4$ years & $2.06(1.44-2.94)$ & \\
\hline \multicolumn{3}{|l|}{ Race } \\
\hline White & 1.00 & \multirow[t]{2}{*}{0.156} \\
\hline Non-white & $0.72(0.46-1.13)$ & \\
\hline \multicolumn{3}{|l|}{ Socioeconomic variables } \\
\hline \multicolumn{3}{|l|}{ Maternal education } \\
\hline$<8$ years of formal education & 1.00 & \multirow[t]{2}{*}{0.000} \\
\hline$\geq 8$ years of formal education & $2.65(1.60-4.38)$ & \\
\hline \multicolumn{3}{|l|}{ Household income in $R \${ }^{c}$} \\
\hline Lowest ( $7^{\text {st }}$ tertile) & 1.00 & \multirow{3}{*}{0.001} \\
\hline Medium ( $2^{\text {nd }}$ tertile $)$ & $0.98(0.63-1.52)$ & \\
\hline Highest ( $3^{\text {th }}$ tertile) & $1.90(1.30-2.76)$ & \\
\hline \multicolumn{3}{|l|}{ Behavior variable } \\
\hline \multicolumn{3}{|l|}{ Dental attendance } \\
\hline No & 1.00 & \multirow[t]{2}{*}{0.000} \\
\hline Yes & $3.62(2.24-5.85)$ & \\
\hline
\end{tabular}

aPrevalence ratio. ${ }^{\text {b95\% }}$ confidence interval. 'Brazilian real exchange rate was $\mathrm{R} \$ 3.75$ to US $\$ 1.00$ approximately). model, children who attended daycare (PR 2.53; 95\%CI 1.39-4.60) and whose parents were members of volunteer networks (RP 1.58; 95\%CI 1.02-2.46) were more likely to use dental floss. Older children ( $\geq 4$ years) presented a higher prevalence of dental floss use (RP 1.77; 95\%CI 1.22-2.55). Considering the socioeconomic variables, children most likely to use dental floss were from families with higher income (RP 1.55; 95\%CI 1.07-2.24) and higher maternal schooling (RP 2.21; 95\%CI 1.31-3.74). When the behavioral characteristic was added to the model, children who attended dental services were more likely to use dental floss (RP 2.33; 95\%CI 1.39-3.90).

\section{Discussion}

The present findings support the hypothesis that environmental and socioeconomic characteristics may be related to the use of dental floss in preschool children. Children who attended daycare and whose parents took part on voluntary networks were more likely to use dental floss. Furthermore, our findings also demonstrated that older children who had visited the dentist and with high socioeconomic level presented a higher prevalence of dental floss use.

Few studies have assessed the relationship between different determinants of dental hygiene. ${ }^{7,23}$ However, the effects of the environment and hierarchical levels on this outcome in preschool children was not explored yet. Children who attended daycare were more likely to use dental floss. These findings are in accordance with a previous study which demonstrates that the school environment has a positive effect on oral health conditions, knowledge consolidation, and incorporation of oral hygiene habits. ${ }^{24}$ In addition, children attending school are more likely to participate in programs for health promotion and have good school habits. ${ }^{24,25,26}$ Thus, attending daycare may be related to a positive influence of the environment in the use of dental floss among children.

A possible explanation for the influence of parental participation in voluntary networks on dental floss use might be related to the importance of social interaction, attributed to a routine within a group of people, which may influence the lives of those 
Table 3. Adjusted association of variables with use of dental floss, determined using Poisson regression with robust variance.

\begin{tabular}{|c|c|c|c|c|}
\hline \multirow{3}{*}{ Variables } & Model $1^{\circ}$ & Model $2^{\mathrm{b}}$ & Model 3c & Model $4^{\mathrm{d}}$ \\
\hline & "Environmental" & "Demographic" & "Socioeconomic" & "Behavior" \\
\hline & $\operatorname{PRe}(95 \% \mathrm{Cl})^{\dagger}$ & PR $(95 \%$ Cl) & PR $(95 \% \mathrm{Cl})$ & PR $(95 \% \mathrm{Cl})$ \\
\hline \multicolumn{5}{|l|}{ Environmental variables } \\
\hline \multicolumn{5}{|l|}{ Attend school } \\
\hline No & 1.00 & 1.0 & 1.0 & 1.00 \\
\hline Yes & $2.53(1.39-4.60)^{* *}$ & $2.11(1.15-3.84)$ & $1.78(0.95-3.31)$ & $1.46(0.79-2.71)$ \\
\hline \multicolumn{5}{|l|}{ Member of volunteer networks } \\
\hline No & 1.00 & 1.0 & 1.0 & 1.00 \\
\hline Yes & $1.58(1.02-2.46)^{*}$ & $1.62(1.06-2.48)$ & $1.53(1.02-2.30)$ & $1.31(0.87-1.97)$ \\
\hline \multicolumn{5}{|l|}{ Demographic variables } \\
\hline \multicolumn{5}{|l|}{ Sex } \\
\hline Female & & 1.00 & 1.00 & 1.00 \\
\hline Male & & $0.76(0.55-1.06)$ & $0.78(0.57-1.08)$ & $0.79(0.58-1.08)$ \\
\hline \multicolumn{5}{|l|}{ Age } \\
\hline$<4$ years & & 1.00 & 1.0 & 1.00 \\
\hline$\geq 4$ years & & $1.77(1.22-2.55)^{* *}$ & $1.86(1.30-2.65)$ & 1.54 (1.08-2.19) \\
\hline \multicolumn{5}{|l|}{ Socioeconomic variables } \\
\hline \multicolumn{5}{|l|}{ Maternal education } \\
\hline$<8$ years of formal education & & & 1.00 & 1.00 \\
\hline$\geq 8$ years of formal education & & & $2.21(1.31-3.74)^{* *}$ & $1.83(1.07-3.11)$ \\
\hline \multicolumn{5}{|l|}{ Household income in $R \$^{g}$} \\
\hline Lowest ( $7^{\text {st }}$ tertile) & & & 1.00 & 1.00 \\
\hline Medium ( $2^{\text {nd }}$ tertile) & & & $0.93(0.61-1.43)$ & $0.99(0.65-1.51)$ \\
\hline Highest ( $3^{\text {th }}$ tertile) & & & $1.55(1.07-2.24)^{*}$ & $1.60(1.11-2.31)$ \\
\hline \multicolumn{5}{|l|}{ Behavior variable } \\
\hline \multicolumn{5}{|l|}{ Dental attendance } \\
\hline No & & & & 1.00 \\
\hline Yes & & & & $2.33(1.39-3.90)^{* *}$ \\
\hline Log pseudo-likelihood & -240.18 & -234.92 & -218.94 & -213.49 \\
\hline
\end{tabular}

Model 1: model with the environmental variables; ${ }^{\circ}$ Model 2: model 1 plus demographic variables; ${ }^{c}$ Model 3: model 2 plus socioeconomic variables; ${ }^{\mathrm{d}}$ Model 4: model 3 plus behavior variable; ${ }^{\mathrm{e} P R}$, prevalence ratio; ${ }^{\mathrm{f}} \mathrm{Cl}$, confidence interval; ${ }^{\mathrm{B}}$ Brazilian real exchange rate was $\mathrm{R} \$ 3.75$ to US $\$ 1.00$ approximately. ${ }^{*}$-value $<0.05 ;{ }^{* *}$-value $<0.01$.

involved. ${ }^{27,28}$ This effect can be due to the social capital involving elements such as the interaction between individuals (social network) and social support. ${ }^{15,27}$ In this sense, high levels of social network can influence health through the spread of healthy norms and health-enhancing behaviors. ${ }^{27}$ Thus, good social networks can be related to good health behaviors, such as use of dental floss.

In this study, we considered household income and maternal education as proxies to individual socioeconomic status. ${ }^{29}$ The finding of negative impact of low household income and poor maternal education is in agreement with a previous study. ${ }^{17}$ Individuals with poor socioeconomic status are more susceptible to general and oral health risk factors. Those people usually have fatalist beliefs and poor self-perceptions of health, which results in poor selfcare. ${ }^{30,31}$ Moreover, deprived individuals may be less likely to engage in healthy behaviors, given their lack of economic resources and empowerment to make healthy choices. ${ }^{32}$ Thus, families and children with lower socioeconomic conditions generally have 
poor behaviors related to oral health and preventive interventions, ${ }^{30,33}$ as found is our study.

Regarding demographic characteristics, older children were positively associated with higher use of dental floss. A previous study showed that younger children brush their teeth less than older ones. ${ }^{23}$ Furthermore, a study that examined the methods used by teachers to facilitate hygiene practices in Early Childhood Education Centers reported that the older pupils taught the younger ones hygiene practices, ${ }^{34}$ indicating that the older the child, the greater the propensity for better oral hygiene habits.

Taking into account the behavioral variable, it was shown that children who attended to the dentist were more likely to use dental floss. A previous study has shown that children from parents who perceived their child's oral health as good had a higher probability to have visited the dentist for preventive care. ${ }^{9}$ Furthermore, another study found that visiting the dentist was a predictor for higher tooth brushing frequency. ${ }^{23}$ Thus, parents that are more attentive tend to ensure a more adequate oral hygiene of their children and take them to preventive dental appointments. This can explain the possible relationship between dental visits and the greater probability of using dental floss.

A limitation of this study is its cross-sectional design, which precludes causal inference. However, cross-sectional studies are important tools for identifying possible indicators to be included in future assessments. Furthermore, data about past clinical variables and parents' knowledge on oral diseases were not included. This may limit our results, since the use of dental floss might be directly related to the history of gingivitis and proximal caries, as well as parent's knowledge about oral disorders. The study strengths include having a representative sample of children of all regions and social classes of the municipality. Furthermore, studying possible promoters of good hygiene habits in preschool children is extremely important to increase the chances of a healthy life, since habits acquired during childhood can persist throughout adult life. ${ }^{17}$ Therefore, the use of dental floss in young children can reduce the incidence of proximal caries and gingivitis in the future.

In conclusion, environmental factors and socioeconomic characteristics are important determinants of the use of dental floss among preschool children. In general, children who live in a more supporting environment and have a higher socioeconomic status are more likely to use dental floss. This indicates the importance of reducing oral health inequalities and planning public health policies aiming to encourage good habits in this population.

\section{Acknowledgments}

The authors thank the children, their parents and health care units for their cooperation, as well as the Health Authorities from Santa Cruz do Sul, Rio Grande do Sul, for all information and authorization.

\section{References}

1. Glick M, Williams DM, Kleinman DV, Vujicic M, Watt RG, Weyant RJ. A new definition for oral health developed by the FDI World Dental Federation opens the door to a universal definition of oral health. Int Dent J. 2016 Dec;66(6):322-4. https://doi.org/10.1111/idj.12294

2. Wagner Y, Heinrich-Weltzien R. Risk factors for dental problems: recommendations for oral health in infancy. Early Hum Dev. 2017 Nov;114:16-21. https://doi.org/10.1016/i.earlhumdev.2017.09.009

3. Blumenshine SL, Vann WF Jr, Gizlice Z, Lee JY. Children's school performance: impact of general and oral health. J Public Health Dent. 2008;68(2):82-7. https://doi.org/10.1111/i.1752-7325.2007.00062.x

4. Thomson WM, Malden PE. Assessing change in the family impact of caries in young children after treatment under general anaesthesia. Acta Odontol Scand. 2011 Sep;69(5):257-62. https://doi.org/10.3109/00016357.2011.554862

5. Piovesan C, Antunes JL, Mendes FM, Guedes RS, Ardenghi TM. Influence of children's oral health-related quality of life on school performance and school absenteeism. J Public Health Dent. 2012;72(2):156-63. https://doi.org/10.1111/i.1752-7325.2011.00301.x

6. Garbin CA, Soares GB, Dócusse FR, Garbin AJ, Arcieri RM. Oral health education in school: parents' attitudes and prevalence of caries in children. Rev Odontol UNESP. 2015;44(5):285-91. https://doi.org/10.1590/1807-2577.0097 
Effect of environmental and socioeconomic factors on the use of dental floss among children: a hierarchical approach

7. Oliveira KM, Nemezio MA, Romualdo PC, Silva RA. Silva FWP, Küchler EC. Dental flossing and proximal caries in the primary dentition: a systematic review. Oral Health Prev Dent. 2017;15(5):427-434. https://doi.org/10.3290/i.ohpd.a38780

8. Shaghaghian S, Zeraatkar M. Factors affecting oral hygiene and tooth brushing in preschool children, Shiraz/Iran. J Dent Biomater. 2017 Jun;4(2):394-402.

9. Machry RV, Tuchtenhagen S, Agostini BA, Teixeira CRS, Piovesan C, Mendes FM, et al. Socioeconomic and psychosocial predictors of dental healthcare use among Brazilian preschool children. BMC Oral Health. 2013 Oct;13(1):60. https://doi.org/10.1186/1472-6831-13-60

10. Schwendicke F, Dörfer CE, Schlattmann P, Foster Page L, Thomson WM, Paris S. Socioeconomic inequality and caries: a systematic review and meta-analysis. J Dent Res. 2015 Jan;94(1):10-8. https://doi.org/10.1177/0022034514557546

11. Lee JY, Divaris K. The ethical imperative of addressing oral health disparities: a unifying framework. J Dent Res. 2014 Mar;93(3):224-30. https://doi.org/10.1177/0022034513511821

12. World Health Organization - WHO. Comission on social determinants of health. Geneva: World Health Organization; 2007.

13. Guedes RS, Piovesan C, Antunes JL, Mendes FM, Ardenghi TM. Assessing individual and neighborhood social factors in child oral health-related quality of life: a multilevel analysis. Qual Life Res. 2014 Nov;23(9):2521-30. https://doi.org/10.1007/s11136-014-0690-z

14. Vettore MV, Aqeeli A. The roles of contextual and individual social determinants of oral health-related quality of life in Brazilian adults. Qual Life Res. 2016 Apr;25(4):1029-42. https://doi.org/10.1007/s11136-015-1118-0

15. Aida J, Ando Y, Oosaka M, Niimi K, Morita M. Contributions of social context to inequality in dental caries: a multilevel analysis of Japanese 3-year-old children. Community Dent Oral Epidemiol. 2008 Apr;36(2):149-56. https://doi.org/10.1111/j.1600-0528.2007.00380.x

16. Hujoel PP, Cunha-Cruz J, Banting DW, Loesche WJ. Dental flossing and interproximal caries: a systematic review. J Dent Res. 2006 Apr;85(4):298-305. https://doi.org/10.1177/154405910608500404

17. Holst D, Schuller AA. Oral health in a life-course: birth-cohorts from 1929 to 2006 in Norway. Community Dent Health. 2012 Jun;29(2):134-43.

18. Instituto Brasileiro de Geografia e Estatística - IBGE. Síntese de indicadores sociais. uma análise das condições de vida da população brasileira. Rio de Janeiro: Instituto Brasileiro de Geografia e Estatística; 2010.

19. Kaver B, Schütz J, Colussi PR, Oppermann RV, Haas AN, Rösing CK. Self-reported use of dental floss over 13 years: relationship with family income, mother's age and educational level. Oral Health Prev Dent. 2016;14(1):33-9. https://doi.org/10.3290/i.ohpd.a34375

20. World Health Organization. Oral health surveys: basic methods. 4th ed. Geneva: World Health Organization; 1997.

21. França-Pinto CC, Cenci MS, Azevedo MS, Goettems ML, Torriani DD, Romano AR. Approximal caries in primary posterior teeth: diagnosis and associated factors. Pesqui Bras Odontopediatria Clin Integr. 2011;11(3):387-92. https://doi.org/10.4034/pboci.v1li3.882

22. WHO. A conceptual framework for action on the social determinants of health. Geneva: World Health Organization; 2010.

23. Agostini BA, Machry RV, Teixeira CR, Piovesan C, Oliveira MD, Bresolin CR, et al. Self-perceived oral health influences tooth brushing in preschool children. Braz Dent J. 2014;25(3):248-52. https://doi.org/10.1590/0103-6440201302426

24. Barros VA, Costa SM, Zanin L, Flório FM. Evaluation of an educational activity in the oral health of students. Int J Dent Hyg. 2017 Feb;15(1):23-9. https://doi.org/10.1111/idh.12152

25. Takeuchi R, Kawamura K, Kawamura S, Endoh M, Uchida C, Taguchi C, et al. Evaluation of the child oral health promotion 'MaliMali' Programme based on schools in the Kingdom of Tonga. Int Dent J. 2017 Aug;67(4):229-37. https://doi.org/10.1111/idj.12293

26. Ghaffari M, Rakhshanderou S, Ramezankhani A, Noroozi M, Armoon B. Oral Health Education and Promotion Programmes: Meta-Analysis of 17-Year Intervention. Int J Dent Hyg. 2018 Feb;16(1):59-67. https://doi.org/10.1111/idh.12304

27. Kawachi I, Berkman L. Social cohesion, social capital, and health. In: Berkman LF, Kawachi I, editors. Social epidemiology. NY: Oxford University Press; 2000. p. 174-90.

28. Pattussi MP, Marcenes W, Croucher R, Sheiham A. Social deprivation, income inequality, social cohesion and dental caries in Brazilian school children. Soc Sci Med. 2001 Oct;53(7):915-25. https://doi.org/10.1016/S0277-9536(00)00391-9

29. Antunes JL, Frazão P, Narvai PC, Bispo CM, Pegoretti T. Spatial analysis to identify differentials in dental needs by area-based measures. Community Dent Oral Epidemiol. 2002 Apr;30(2):133-42. https://doi.org/10.1034/j.1600-0528.2002.300207.x

30. Finlayson TL, Siefert K, Ismail Al, Sohn W. Maternal self-efficacy and 1-5-year-old children's brushing habits. Community Dent Oral Epidemiol. 2007 Aug;35(4):272-81. https://doi.org/10.1111/i.1600-0528.2007.00313.x

31. Freire MC, Reis SC, Figueiredo N, Peres KG, Moreira RS, Antunes JL. [Individual and contextual determinants of dental caries in Brazilian 12-year-olds in 2010]. Rev Saude Publica. 2013 Dec;47(3 Suppl 3):40-9. Portuguese. https://doi.org/10.1590/S0034-8910.2013047004322 
32. Braveman PA, Cubbin C, Egerter S, Chideya S, Marchi KS, Metzler M, et al. Socioeconomic status in health research: one size does not fit all. JAMA. 2005 Dec;294(22):2879-88. https://doi.org/10.1001/jama.294.22.2879

33. Vann WF Jr, Lee JY, Baker D, Divaris K. Oral health literacy among female caregivers: impact on oral health outcomes in early childhood. J Dent Res. 2010 Dec;89(12):1395-400. https://doi.org/10.1177/0022034510379601

34. Kerich JC, Sang H, Kipkosge A. Teaching methods used by teachers to facilitate hygiene practices in early childhood education centers in Londiani Sub-County. Int J Sci Res Public. 2017 Oct;7(10):165-71. 